\title{
2006-525: PROJECT BASED ACTIVE LEARNING INVOLVING FRESHMAN AND SOPHOMORE ENGINEERING MAJORS AT UNIVERSITY OF MARYLAND EASTERN SHORE
}

\section{Abhijit Nagchaudhuri, University of Maryland-Eastern Shore}

Dr. Abhijit Nagchaudhuri is a Professor in the Department of Engineering and Aviation Sciences at University of Maryland Eastern Shore. He is active in teaching and research in the fields of engineering mechanics, mechatronics, control systems and remote sensing. He obatined his M.S. degree from Tulane University in 1989 and Ph.D. degree from Duke University in 1992.

Whitney Smith, UMES/Rutgers University

Ms. Smith was an engineering student at UMES during the 2003-2005 academic years. She is now a Junior at Rutgers University in the Biomedical Engineering Department

Uditha Poddalgoda, University of Maryland-Eastern Shore

Undergraduate Student at University of Maryland Eastern Shore ( Mechanical). Currently a Junior at University of Minnesota mechanical engineering program

Amy Jarrett, University of Maryland-Eastern Shore Undergraduate Student at University of Maryland Eastern Shore ( Mechanical)

Omar A. Omar, University of Maryland-Eastern Shore Undergraduate Student at University of Maryland Eastern Shore ( Mechanical)

Aaron Redden, University of Maryland-Eastern Shore Undergraduate Student at University of Maryland Eastern Shore ( Civil)

Daniel Seaton, University of Maryland-Eastern Shore

Dr. Daniel M. Seaton is currently an Assistant Professor of Mathematics in the Department of Mathematics and Computer Science at University of Maryland Eastern Shore. Dr. Seaton is Co-PI of the NSF supported HBCU-UP grant at UMES.

\section{Robert Johnson, University of Maryland-Eastern Shore}

Dr. Robert Johnson, Jr. is an Associate Professor of Mathematics in the Department of Mathematics and Computer Sciences and a Co-PI of the NSF supported HBCU-UP grant at University of Maryland Eastern Shore 


\title{
Project Based Active Learning Endeavors for Freshman and Sophomore Engineering Majors at University of Maryland Eastern Shore
}

\begin{abstract}
With support from HBCU-UP (Historically Black College and University - Undergraduate Program) at National Science Foundation (NSF), the ACTION (Advanced Curriculum and Technology-Based Instructional Opportunities Network) program at University of Maryland Eastern Shore (UMES) is promoting inquiry based active learning and research projects among undergraduate STEM (Science, Technology, Engineering and Mathematics) majors. This paper highlights efforts of selected freshman and sophomore engineering majors while performing ACTION projects at UMES. Integration of Lego-Mindstorm Robotic Invention System as well as ProEngineer and ProMechanica software for solid modeling and analysis are the focus of the reported endeavors. Involvement in ACTION projects have not only reinforced concepts introduced in classroom setting but have inspired students to be engaged in the process of learning and discovery well beyond expectations of the course syllabi, format, and structure.
\end{abstract}

\section{Introduction}

Undergraduate research projects provide students with opportunities to think like a scientist or engineer, ${ }^{[1]}$ increases student participation in interdisciplinary, authentic problem solving ${ }^{[2]}$ and help universities move from teaching oriented to learning centered. ${ }^{[3]}$

The "Academic Excellence" [4] study reveals the value that all institutions place on undergraduate research. Twenty - five (25) percent of all published papers include student authors. Undergraduate research is a way of focusing and guiding the undergraduate experience, rather than solely serving as a preparation for graduate school, and is a major opportunity to demonstrate to accreditation agencies and other organizations that students are performing at enhanced levels. ${ }^{[5]}$

Undergraduate research programs are held on numerous colleges and universities nationally. A substantial number of universities have begun to realize that undergraduate research is a real asset, thus they are identifying more resources and expanding opportunities to involve more students. ${ }^{[6]}$ Consequently, UMES designed the Advanced Curriculum and Technology-Based Instruction Opportunities Network $(A C T I O N)$ sponsored by the National Science Foundation to support a variety of initiatives to improve undergraduate experiences in the STEM disciplines including the Complete Research Cycle (CRC). The CRC provides opportunities for STEM students, along with their faculty mentors, a complete exposure to the common aspects associated with sponsored research. Too often, undergraduate research projects are concluded without formally presenting results in scholarly venues including professional meetings, 
conferences, and journals. This practice fails to position students for employment or graduate study and neglects the value of undergraduate research programs to attract support from internal and external resources to extend results through further research. Although preparing students for further graduate study is a priority for the ACTION Program, instilling research and professional demeanor in undergraduate students serves them well in the instance that they seek career opportunities in the industrial or research marketplace.

The CRC emphasizes inquiry-based activities, development of research interest, formulation of proposed activities to attract support, sustained periods of investigation, and presentation of results. The CRC is consistent with the preparation, presentation, and publication sequence identified as essential by Nnadozie, Ishiyama, and Chon as early as 1983. ${ }^{[7]}$ The major components of the UMES MSEIP CRC are outlined below:

a. Grant Proposal Preparation. To simulate the sponsored research environment, a request for proposals (RFP) was developed and released to faculty and students in the STEM departments seeking financial and support resources to complete undergraduate research.

b. Creating a Research Environment. Approved proposals received funding to support summer stipends to both faculty and students, materials and equipment needs, travel to regional and national competitions and conferences, and publication costs. During this period of sustained research, students were encouraged to submerge themselves completely in the project, develop timelines and milestones, and contingencies. Faculty assumed responsibility for reporting and management responsibilities along with other advisement duties.

c. Articulating Results. The MSEIP Program hosted a research exposition where students' presentations of the findings of supported projects. Student Showcase provides a public forum that reflects the quality of the research experience for students and faculty alike. ${ }^{[5]}$

d. Preparing Results for Publication. The University of Maryland Eastern Shore Science, Engineering, and Technology Research Proceedings archives final versions of the student/faculty research projects thereby extending and preserving the quality of faculty and student achievement. Papers were submitted to the editorial board before publication providing students with opportunities to experience the traditional peer-review process that generally precedes scholarly publication.

This paper documents efforts pertaining to two such ACTION projects that the primary author has supervised since the inception of the program at UMES. The first of these projects titled: CAD assisted Assembly and Programming of Mobile Platforms involved undergraduate students, Mr. Uditha Poddalgoda and Ms. Whitney Smith through the Complete Research Cycle in the fall semester of 2004 and spring semester of 2005. Ms. Amy Jarret, Mr. Omar A. Omar and Mr. Aaron Redden forms the undergraduate student team for the second project titled: Exploring Mechanics of Material Principles using ProMechanica and MDsolids Software Packages. At the time of writing this paper, the first phase of this two semester project that runs through fall of 2005 and spring of 2006, has been completed. 
In recent years sweeping changes and improvements have been made in Computer Aided Design (CAD) as well as Computer Aided Manufacturing (CAM). Several solid modeling packages have been developed which have vastly improved visualization and design analysis capabilities with a significant impact in the product development process. Almost all engineering industries are adopting the powerful solid modeling packages available in the market over the conventional two-dimensional drafting environments in their new product development endeavors. It becomes extremely important, for most engineering majors, to have a strong foundation in utilizing one or more solid modeling packages, however, credit hour constraints and general limitation associated with classroom instruction, seldom allows adequate time to be devoted to such efforts. A significant number of undergraduate students and in particular minority students work to earn part of their expenses between class hours. Out of classroom projects and experiential learning and research efforts such as the ones described, not only reinforces classroom instruction, but also provides financial incentives for students to be involved with academic enrichment endeavors. Such involvement provides additional time to acquire skills, reinforce learning, as well as, perform investigations on areas that are relevant, and consistent with modern industrial practices. Although, this paper and the projects described, focuses on solid modeling and computer aided design using ProEngineer Wildfire software package (developed by Parametric Technology Corporation ${ }^{[8]}$ ), the dynamic nature of engineering practice and the intensive infusion of modern technology necessitates similar efforts in almost every aspect of engineering education.

In the sections that follow an introduction and descriptions of two ACTION projects supervised by the primary author are provided, followed by impact on educational goals. The paper also discusses possible project extensions and ends with a section on conclusion.

\section{CAD assisted Assembly and Programming of Mobile Platforms}

The two semester long project was divided in four phases. Phase-I consisted of purchasing necessary kits and software including Lego Mindstorm Robotic Invention System kit, Solar Car

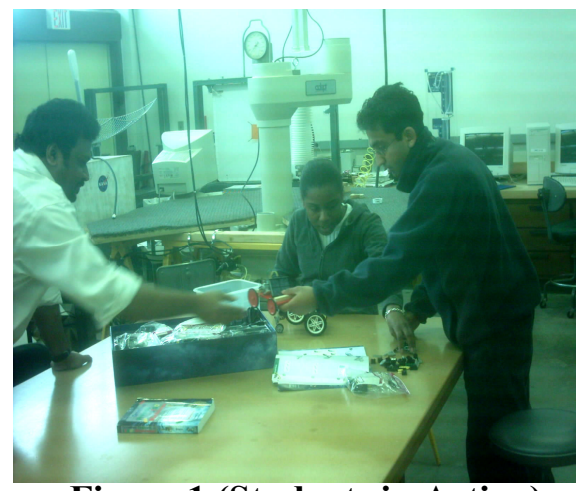

Figure 1 (Students in Action) kit and ProEngineer Wildfire software, as well as, developing a realistic project time line using a Gantt chart. Phase-II was devoted to assembling the kits to develop appropriate devices and coming up with best assembly sequence for each device. Figure 1 shows student participants and the faculty advisor during the initial stages of Phase-II. Advanced features of ProEngineer Wildfire environment pertaining to assembly and animation of assembly sequence were also explored in this phase. In Phase-III solid models of each component of Lego kit and Solar Car kit were developed in the ProEngineer environment. Following the best assembly sequence identified in Phase -II, assembly of the components were performed to develop threedimensional solid models of these devices in the CAD environment. The primary author (project advisor) received significant support from a senior student ${ }^{[9]}$ and a mechanical engineering faculty member ${ }^{[10]}$ at University of Maryland College Park (UMCP) in this phase of the project which allowed the student participants to achieve the desired objectives in time. The visual 
photographs of these two assembly kits and their respective three-dimensional solid models are shown in Figures 2 through 5.

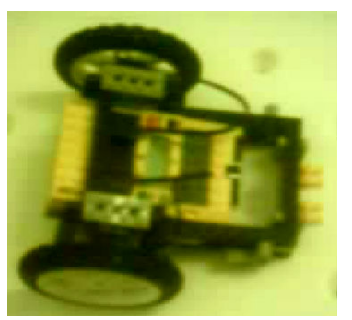

Figure 2- Photo

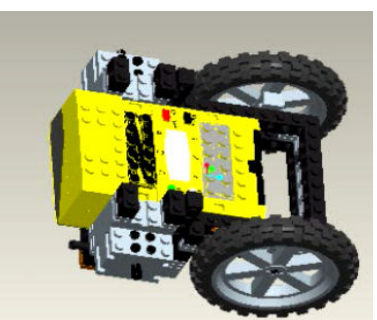

Figure 3 - ProE

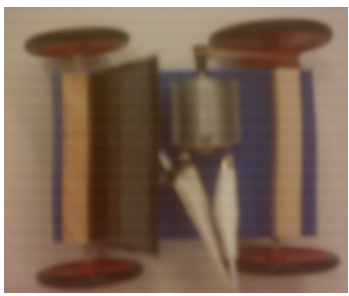

Figure 4 -Photo

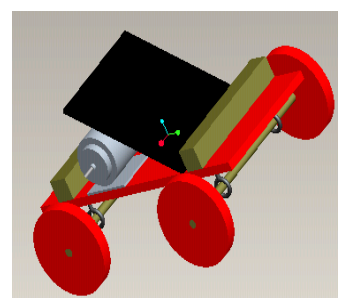

Figure 5 - ProE

In Phase-IV the student participants used the animation feature of the software environment to animate the assembly process in the software environment according to identified assembly sequence. Appropriate time intervals and interpolation techniques were utilized to generate a

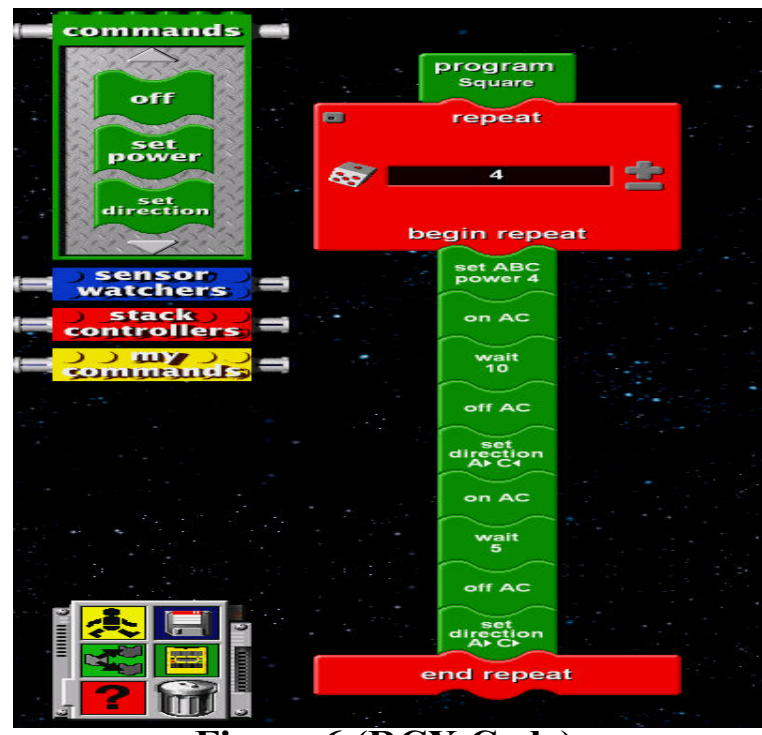

Figure 6 (RCX Code)

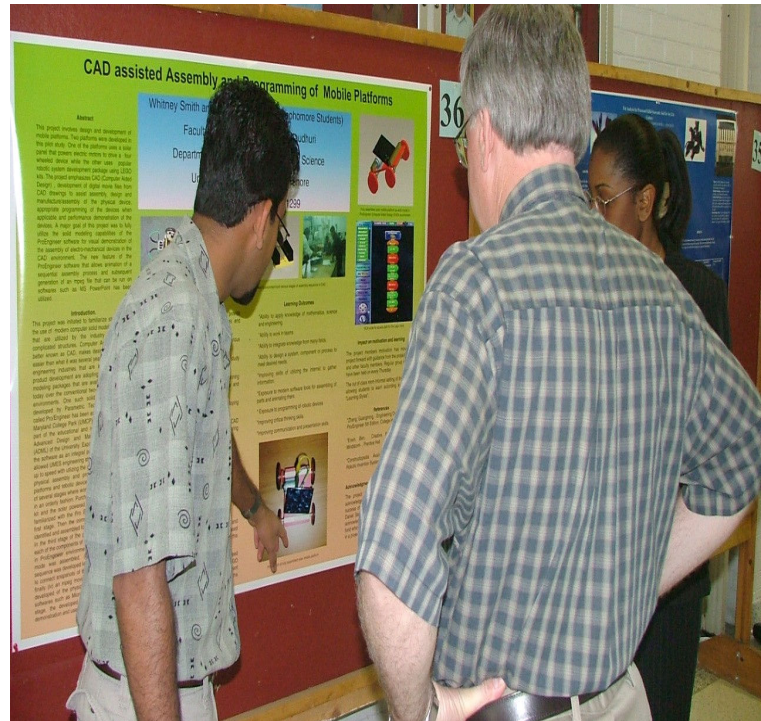

Figure 7 (HBCU Research Day at UMES) movie file (MPEG) of the assembly sequence from within the ProEngineer environment. In this phase the student participants also devoted some of their effort in learning software tools such as RCX-code, Robolab, and Not Quite C (NQC) ${ }^{[11]}$ to program desired motion segment for the Lego based robotic device developed. The RCX-code sequence for making a square trajectory for the Lego-robot is shown in Figure 6. In this phase the student participants gained valuable experience in preparing posters as well as presenting their work during the HBCU research day hosted on UMES campus in April 2005. Figure 7 shows the student participants explaining aspects of their project during the poster presentation.

The learning outcomes of the project are listed below and are consistent with those emphasized by Engineering Criteria 2000 of ABET ${ }^{[12]}$ (Accreditation Board of Engineering and Technology):

(i) Learning to work effectively in a team.

(ii) Developing programming skills in RCX-Code and Robolab

(iii) Extensive use of the ProEngineer software package

(iv) Exploration of design and assembly process

(v) Improved preparation for succeeding with open ended problems in future courses. 
(vi) Experience with developing project reports and project presentation.

(vii) Improved ability to initiate and work a project through to completion.

(viii) Valuable insight into engineering design process and the role played by solid modeling packages in design and visualization during the product development stage.

(ix) Exploration of the renewable energy resources that will play a significant role in sustainable engineering of the future.

(x) Ability to effectively interface with advisor as well as project partner for project execution.

While formal assessment of the learning outcomes were not integrated in the project, the participants did fill out a survey at the end of the project, the survey, as well as, anecdotal evidences and informal observations by the project advisor substantiate that the desired goals were positively impacted.

Subsequent to completion of the project, during a middle school outreach effort that the project advisor co-directs, the movie of the animation assembly sequence was utilized to assist middle school student teams to perform similar assembly tasks with considerable success.

The extension possibilities of the project include:

(i) Exploring other capabilities of the ProEngineer environment.

(ii) Learning Not Quite C and JAVA for implementation on Lego Robots.

(iii) Exploring other renewable energy sources such as fuel cell, wind power etc.

(iv) Improving animation sequencing and movie file of the assembly process using feed back from middle school students.

(v) Exploring the world of Computer Aided Manufacturing (CAM) and possible development of a state of the art CAD CAM facility at University of Maryland Eastern Shore (UMES).

The second ACTION project described in this paper addresses the first of the extension possibilities listed above. The project utilizes a software environment titled MDSolids as well as ProMechanica. ProMechanica is an integral component of the ProEngineer Wildfire software that allows stress analysis of solid models developed in ProEngineer environment, under appropriate loading.

\section{Exploring Mechanics of Material Principles using ProMechanica and MDsolids Software Packages}

MDsolids is a software program developed by an engineering faculty member. It has been well received by students and faculty in engineering classrooms. The software provides visual and analysis tools to reinforce complex concepts in courses such as Statics and in particular Mechanics of Materials ${ }^{[13]}$ which are core requirements for most engineering majors.

ProMechanica allows solid models developed in ProEngineer ${ }^{[14]}$ to be appropriately constrained and loaded for subsequent stress and deformation analysis. ProMechanica utilizes finite element analysis approach. It can also interface with other popular finite element analysis packages such as ANSYS and NASTRAN. 
This ACTION project consists of two phases beginning in fall semester of 2005 through end of spring semester of 2006. In the first phase, during the fall semester of 2005, interested students in the sophomore level class of Mechanics of Material (ENES 220) were introduced to stress analysis using finite element analysis using ProMechanica software package. This phase of the ACTION project was integrated with the project requirement in the ENES 220 course and has just been completed prior to writing this paper. Students have worked in teams to perform stress analysis using MDsolids ${ }^{[15]}$ and ProMechanica software and confirmed the results using hand calculations. Some of the analysis results are shown in Figures 8 through 10. Figures 8 and 9 show stress and deformation analysis involving MDsolids and ProMechanica for a solid shaft of 2 inches outer diameter and length of 5 inches subjected to torsion load of 100 kip-in, Material of the shaft is assumed to be aluminum with a modulus of rigidity of 3,900 ksi. By using appropriate formula the shear stress and deformation is easily calculated as:

$$
\begin{aligned}
& \tau=\mathrm{T}^{*} \mathrm{C} / \mathrm{J}=\left(100^{*} 1\right) /\left(\pi / 2 *(1)^{\wedge} 4\right)=63.66 \mathrm{kip} / \mathrm{in}^{\wedge} 2=63.66 \mathrm{Ksi} \\
& \text { (ii) } \Phi=\mathrm{T} \mathrm{L} / \mathrm{J} \mathrm{G}=\left(100^{*} 5\right) /\left(\pi / 2 *(1)^{\wedge} 4 *(3900)\right)=0.0816 \mathrm{rad} .
\end{aligned}
$$

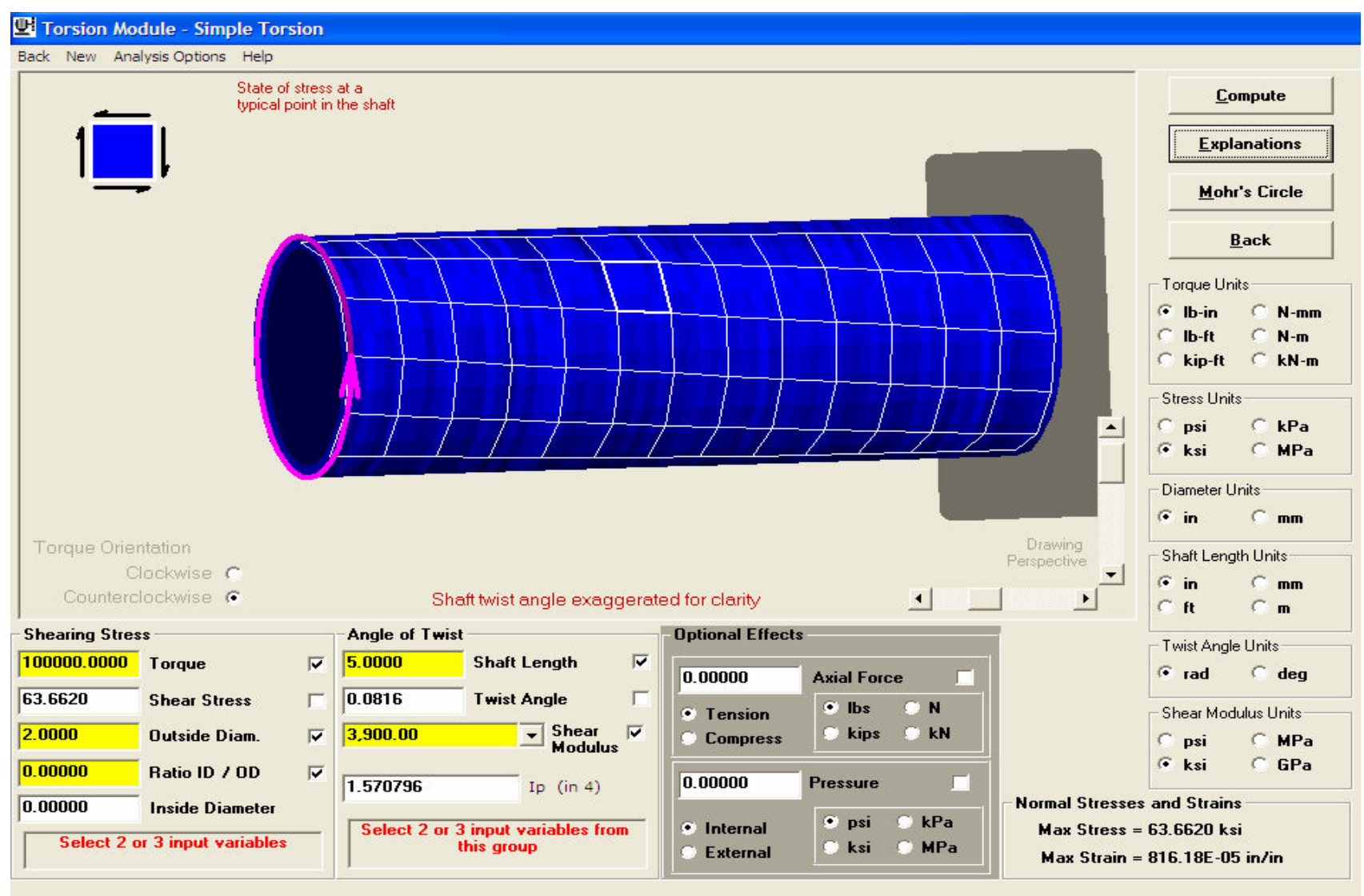

Figure 8 (MDSolids)

These results are readily obtained using MD solids as shown in Figure 8. The results obtained using finite element analysis using ProMechanica are $63.69 \mathrm{ksi}$ and 0.0812 radians as shown in Figures $9 \mathrm{a}$ and $9 \mathrm{~b}$. It may be noted, ProMechanica obtains not only solutions for maximum values of stress and deformation but also the stress and deformation results for all portions of the shaft. 


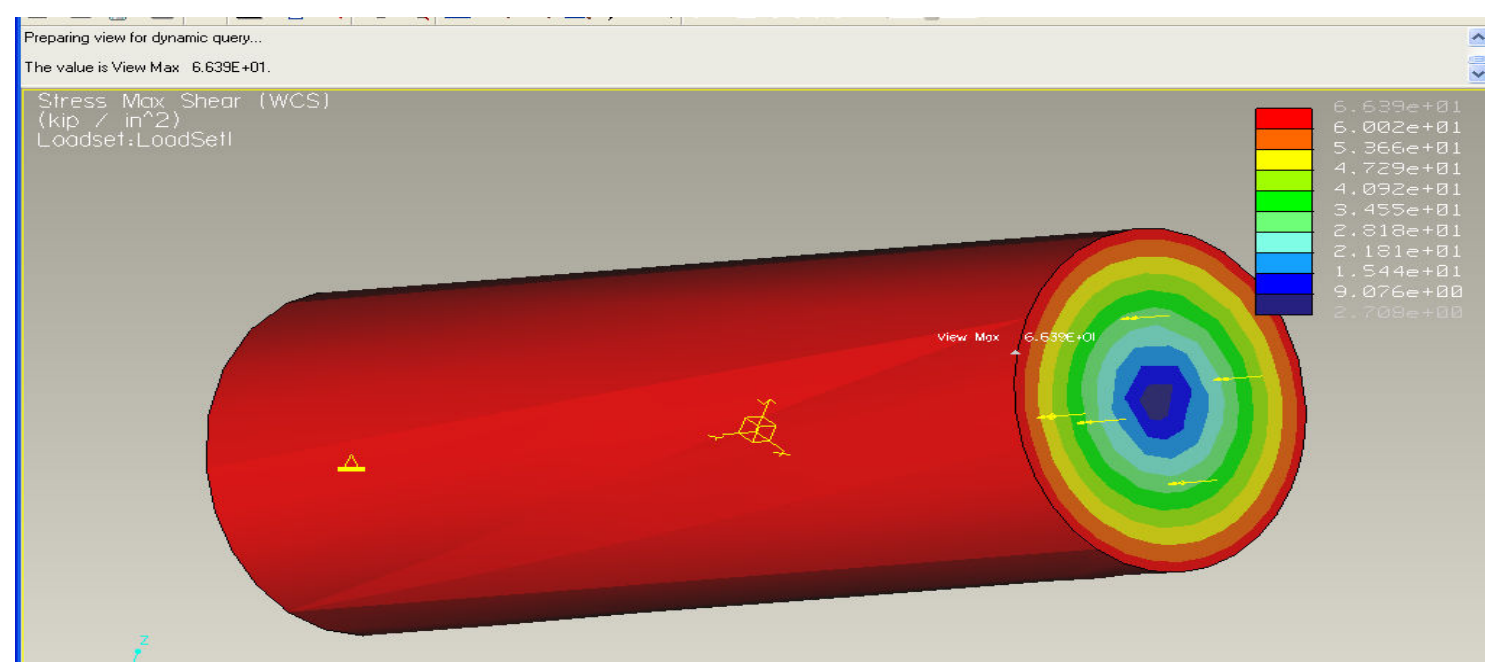

Figure 9a ( Stress- ProMechanica)

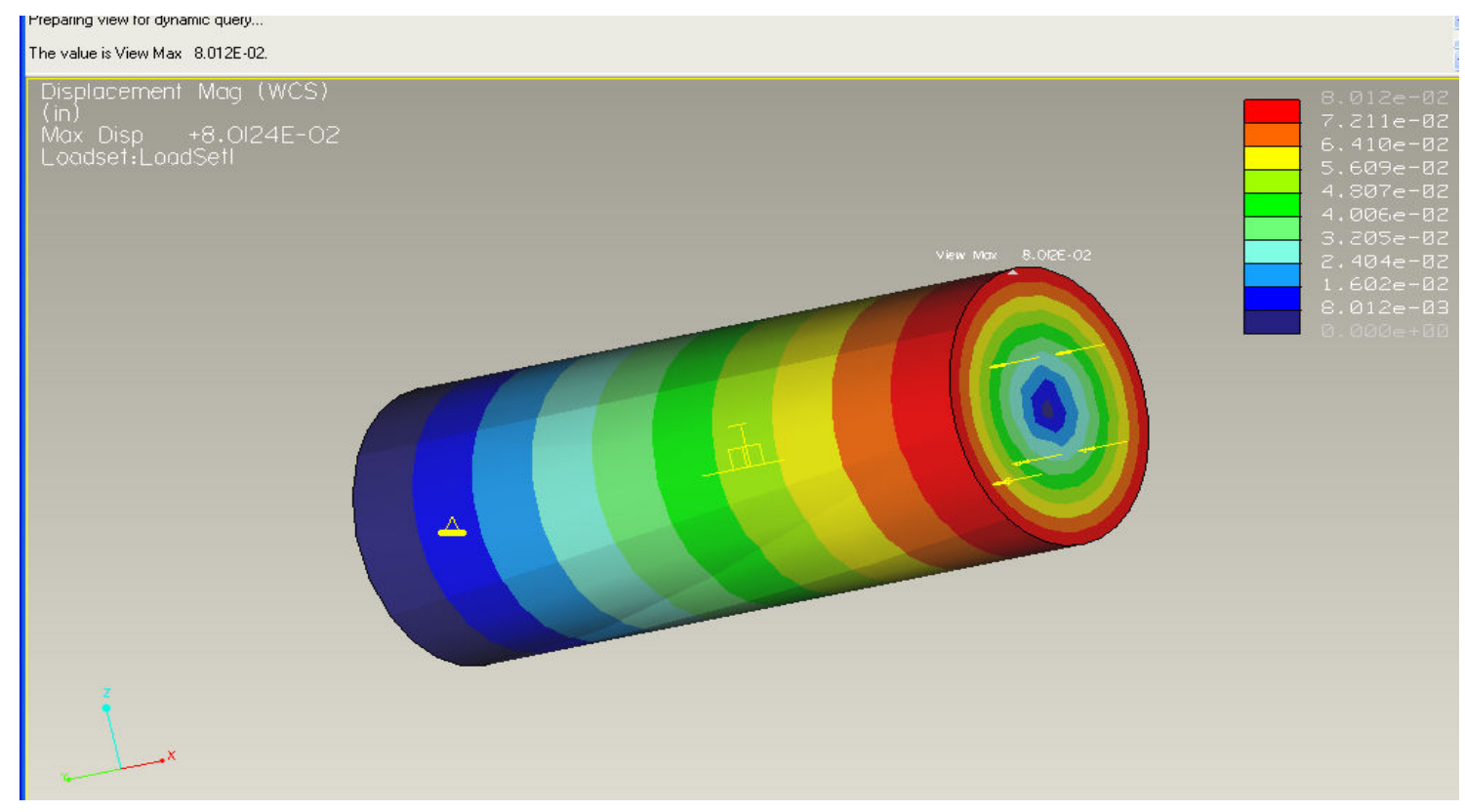

Figure 9b (Deformation - ProMechanica)

Complex stress patterns are clearly visible in Figure 10 for a thin plate with a fillet and a hole subjected to normal load. The stress concentration effects near the hole and the fillet are clearly visible in the stress patterns and are consistent with discussion provided in ${ }^{[13]}$ that was used as text in the ENES 220 course. The results obtained using ProMechanica (Figure 10) could be easily verified by using stress concentration factor and appropriate formula. 


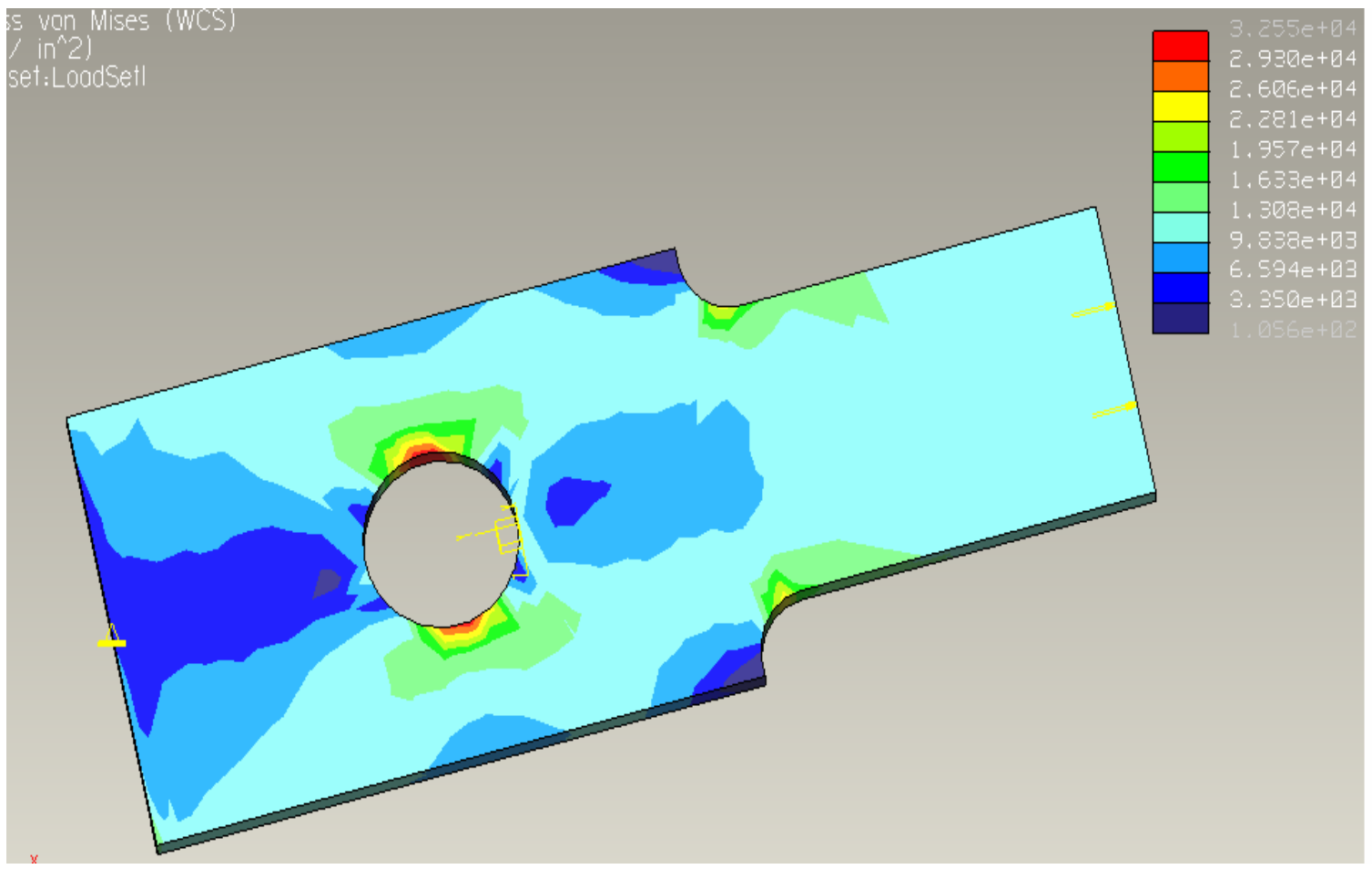

Figure 10 (Stress Concentration)

The following dimensions and load magnitudes were used for the example shown: $\mathrm{w}=1.875$ ', (wider plate portion before fillet $\mathrm{h}=1.25^{\prime}$ '(narrower portion of plate after fillet, $\mathrm{r}$ (radius of fillet $)=0.25$ ', $\mathrm{r}$ (radius of hole $)=0.375$ ', $\mathrm{t}$ (thickness of plate $)=0.125$ ', $\mathrm{P}=2 \mathrm{kip}$ ( normal loading applied at one of the edges of the bar with the other end fixed).

The following equations were used: $\sigma_{\max }($ fillet $)=\mathrm{k}^{*} \sigma_{\mathrm{avg}}, \sigma_{\text {avg }}($ fillet $)=\mathrm{P} /(\mathrm{h} * \mathrm{t}), \sigma_{\text {avg }}(\mathrm{hole})=\mathrm{P} /((\mathrm{w}-$ $\left.2 \mathrm{r})^{*} \mathrm{t}\right)$ and the stress concentration factors were obtained from charts provided in reference ${ }^{[21]}$.

Solving these equations the following values were obtained as $\sigma_{\max }($ fillet $)=22.08 \mathrm{kip}$ and $\sigma_{\max }($ hole $)=34.8 \mathrm{kip}$

Using the the dynamic query feature the corresponding values of stress at the fillet and hole were obtained as $\sigma_{\max }($ fillet $)=22.8 \mathrm{kip} \quad \sigma_{\max }($ hole $)=32.5 \mathrm{kip}$.

The differences are small and well within acceptable margins.

Accurate results (within acceptable variation range) were also obtained using finite element analysis with ProMechanica, by the project participants, using square instead of circular shaft for the torsion analysis [ Figures 11a \& 11b] and by varying the fillet and hole radii for studying stress concentration effects on a plate. In all cases appropriate sections of the text ${ }^{[13]}$ was referenced to reinforce comprehension and deeper conceptualization. 


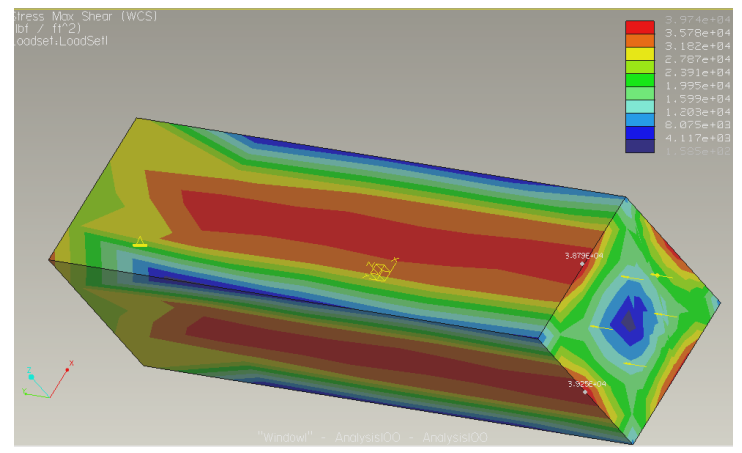

Figure 11a (Stress - Square Shaft)

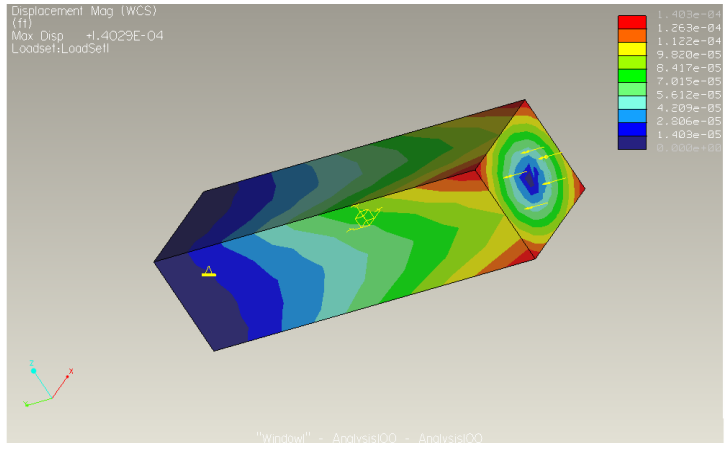

Figure 11b (Deformation-Square Shaft)

At the end of the semester the student participants presented the project results as a powerpoint presentation as well as prepared a technical report to complete the Phase-I efforts. In Phase-II the student participants will work with interested students in Statics (ENES 102) course offered by the principal author in fall semester of 2006 to design a simple machine subject to appropriate space, weight, and cost constraints. The force and moment analysis aspect of an appropriate simple machine will be performed by students in the Statics course in consultation with the project participants. Each part of the machine will be subsequently developed as a solid model in ProEngineer for design analysis using ProMechanica. Selection of appropriate material and cross section will be included in the analysis for comprehensive design optimization subject to cost, space and weight constraints. The Phase-II will be completed during the spring semester of 2006 and refined in the early part of summer of 2006.

The learning outcomes of this project are listed below:

(i) Reinforcement of knowledge gained in the classroom,

(ii) Improved technical writing and oral communication skills

(iii) Acquiring skills with engineering software tools to enhance learning consistent with state of the art practices in engineering industry.

(iv) Ability to use techniques and skills relevant to modern engineering practice to design machine elements and simple machines.

If all goes well the project participants will attend the 2006 ASEE Annual Conference in Chicago and present their work. The exposure will provide valuable experience to the students as well as allow them to make contacts with engineering faculty and administrators, engineering professionals, vendors and other individuals that may support their professional goals and learning experiences.

The project will provide a foundation for design analysis of complex engineering systems subjected to static loading. Stress variation due to dynamic loading is more complex and can be modeled and developed using ProMotion along with ProMechanica and will be pursued in the future as a possible project extension. 


\section{Conclusion}

Simulating engineering problems in software environment provides a cost effective way of learning without having to invest in design and manufacturing efforts with real hardware. The software tools go a long way in reinforcing concepts learned in classroom setting. Such efforts also fuels creativity by allowing students to learn by "what if" approach. Moreover, modern industrial practice depends heavily on visualization and design analysis using software tools.

In the projects described the emphasis has been primarily on integrating advanced features of a popular solid modeling package through freshman and sophomore engineering courses relevant to most engineering majors, and in particular civil, aerospace, and mechanical engineering majors. Out of classroom involvement of the students provide significant enrichment of course related outcomes.

\section{Acknowledgment}

The Complete Research Cycle (CRC) framework of the ACTION program has contributed significantly to improve academic vitality in the UMES campus. Motivated undergraduate STEM majors are utilizing this vehicle to enrich their knowledge, skills, and research potential. The compensation associated with involvement in ACTION project have allowed economically disadvantaged students to participate. The project members wish to appreciate and acknowledge the support rendered towards the success of the project by the Co-Principal investigators Dr. Robert Johnson, and Dr. Dan Seaton as well as Ms Linda Baines (program manager) of the Mathematics Computer Science Department at UMES. The authors are also grateful to NSF HBCU-UP grant for providing the necessary expenses and stipends to perform the work described.

\section{Bibliography}

1. Bradburn, T. Cooperative education: A key link between industry and engineers in the making. Chem Eng Ed. 200;35:58-61.

2. Freeman A. Student research project approaches: The mathematics educator's role. Intl J of Math Ed in Sci and Tech. 1980;11:193-6.

3. Malachowski M. A research across the curriculum movement. New Directions for Teaching and Learning. 2003;93:55-68.

4. Research Corporation. Determining Publication Productivity and Grant Activitiy Among Science Faculty and Surveyed Institutions. Academic Excellence: A Study of the Role of Research in the Natural Sciences at Undergraduate Institutions. Special Report. Tucson, AZ. 2001 (ERIC Document Reproduction Service No. ED469492)

5. Chapman D. Undergraduate research: showcasing young scholars. Chronicle of Higher Education. 2003;50:9.

6. Katkin W. The Boyer Commission Report and its impact on undergraduate research. New Directions for Teaching and Learning. 2003;93:55-68.

7. Nnadozie E, Ishiyama J, Chon J. Undergraduate Research Internships and Graduate School Success. 2001 (ERIC Document Reproduction Service No. ED4555465) 
8. Parametric Technology Corporation, Available Online : http://www.ptc.com/

9. Rosenweig, J. (UMCP Student), Personal Communication, 2004/2005

10. Zhang, G., (UMCP Faculty), Electronic Correspondence, 2004/2005.

11. Baum, David. Definitive guide to Lego Mindstorms. Second Edition, New York. 2003

12. Paterson, D.G., "Engineering Criteria 2000: A Bold New Change Agent", ASEE PRISM, Sept. 1997

13. Hibbler, R.C., Mechanics of Material, Prentice Hall Publishers

14. Guangming, Zhang, Engineering Design and ProEngineer, College House Publisher.

15. Philpott, T., MDSolids Software, Available Online : http://www.mdsolids.com/ 